\title{
RESOURCE CLASSROOM AS A MODEL FOR ORGANIZING INCLUSIVE EDUCATION IN THE RUSSIAN FEDERATION
}

\author{
Olga Bliznyuk \\ Research University «Moscow Power Engineering Institute» \\ (Branch) in Smolensk, Russian Federation \\ Nikolay Senchenkov \\ Smolensk State University, Russian Federation
}

\begin{abstract}
On the basis of inclusive education importance for children with disabilities and special educational needs, which contributes to the development of communication and socialization skills, as well as the development of tolerance among typically developing children, the aim of this work was to describe a resource classroom as a model for the effective organization of inclusive education in mainstream schools of the Russian Federation. The article defines a resource classroom in Russian educational system. The authors determine legal and regulatory frameworks to establish such classrooms. This study presents the main methodological base of resource classrooms, the organization for the educational process and space according to the students needs. Based on the generalization for the experience of the resource classrooms in the regions of the Russian Federation, the interaction for all elements of this model is shown. The study confirms that positive learning outcomes, involvement and inclusion of children with disabilities and special educational needs in a mainstream school and society are the evidence for the effectiveness of resource classrooms. The described model makes inclusion in education comfortable and effective not only for students of the resource classroom, but also for typically developing children, parents and the teaching staff of a school. Keywords: children with disabilities and special educational needs, effective model, inclusive education, mainstream schools, resource classroom, special educational conditions, space organization.
\end{abstract}

\section{Introduction}

Changes in the perception about the rights and needs of children with disabilities have led to the recognition for the right of such children to receive education and define inclusive education as the most humane and effective means of education in many countries such as the USA, Canada, the UK, Germany, Finland, Russia, etc. In the conditions of social economic progress of the society the problem of inclusive education in mainstream schools becomes urgent. M. Farrell considers inclusive education having a great social impact not only on 
children with disabilities and special educational needs, but on their typically developing peers as well, since, inclusion can be a tool for tolerant attitude development, communication and socialization (Farrell, 2003). Therefore, inclusive education is one of the main objectives facing Russian education policy and social protection. Federal Law of December 29, 2012 No. 273-FZ “On Education in the Russian Federation" and the letter of the Ministry of education of the Russian Federation of July 7, 2017 No.TC-267/07 "About information direction" allow organizing teaching and learning of children with disabilities and children with special educational needs in regular educational institutions, which should create special conditions to improve the system of education, develop effective strategies, methods, tools, technologies and models in accordance with the needs and characteristic features of students.

A resource classroom can be an effective model to provide students with disabilities and special educational needs with their right to study at mainstream schools in Russia. The aim of these classrooms is to help students with disabilities or students with special educational needs to adapt to mainstream schools requirements and conditions, get additional help in studying a curriculum, be taught individually or in a small group according to adapted curriculum which meets their learning needs, get help from specialists (psychologists, speech pathologist etc.) and relax.

\section{Theoretical ground}

In Russia the idea of inclusion originates in the 20-30s of the twentieth century from the understanding of integration appeared in pedology. It made a significant contribution to the development of the integration approach in pedagogy. Among the most famous Russian researchers-pedologists are M. Basov (2007), P. Blonsky (1929), V. Kashchenko (2010), A. Lazursky (1910), A. Luria (1973), L. Vygotsky (1936), etc. An outstanding Russian scientist L. Vygotsky indicated the necessity to create a system of education and learning in which a child with disabilities would not be excluded from the society of typically developing children, and he also suggested that the task of raising children with disabilities was their integration into the society (Vygotskiy, 2012). Therefore, he was one of the first Russian researchers who proved the idea of integration which then led to understanding of inclusion.

Today among modern Russian researchers dealing with the problem of inclusion and inclusive education we can name S. Alekhina (2013, 2016), N. Ivanova (2011), A. Liferov (1997), E. Yarskaya-Smirnova and I. Loshakova (2003), N. Malofeev (2009), E. Kutepova (2015), E.A. Yekzhanova (2011), etc.

They consider inclusion to be the central idea in the development of modern education, it affects the value changes of the society. Inclusion is based on the 
idea of the inclusive society. It means that any person (despite their race, religion, culture, abilities) can be included into social relations.

Inclusive education is defined by I. Loshakova and E. Yarskaya-Smirnova as education of children with disabilities and special educational needs together with typically developing peers in mainstream schools (Loshakova \& YarskayaSmirnova, 2002). They point out that the idea of this education is to receive not only education and psychological adaptation in society, but to interact actively with typically developing children. Such communication is also of great importance for children who have no any deviations in their development and health. Thus, this fact significantly increases the role of inclusive education, which allows expanding the opportunities for socialization of children with disabilities and special educational needs.

The law of the Russian Federation "On education” allows educating children with disabilities and special educational needs. According to the law parents or legal guardians have the right to choose the form of education and the educational institution (Federal law, 2012).

There are currently three approaches to the problem of education for children with disabilities and special educational needs in the Russian Federation: the first is education in special (remedial) institutions; the second is integrated education in mainstream schools where children with disabilities and special educational needs attend mainstream schools but study in special classes; the third is inclusive education.

Inclusive approach to education in modern Russia is fundamentally possible, but practically difficult to implement. S. Alekhina states that inclusion of children with disabilities and special educational needs into mainstream schools causes difficulties and problems not only for these children but for the mainstream school teachers as well (Alekhina, 2013). Mainstream teachers need help from special education teachers to organize the process of education effectively taking into account all special features and peculiarities of the excepted children. They should learn how to work and communicate with students with disabilities and special educational needs. S. Alekhina stresses that in educational practice there is a necessity in different educational models for inclusive education which combine collaboration and interaction between mainstream teachers and special education ones (Alekhina, 20016).

A resource classroom can be one of the educational models for organizing inclusive education which comprises the experience and knowledge of special education teachers and mainstream teachers to make this process easier and to solve the problems arising in the learning and teaching processes.

As Russian pedagogy lacks for technologies and methods in the system of inclusive education this model is based on the experience of resource rooms in the USA and Great Britain. In Britain and in the USA a resource room is understood 
as a specially organized space for students learning development and the regulation of their psycho-emotional state (Inclusion of Students with Special Educational Needs, 2007). In this room they can also get any additional help in case they have difficulties with curriculum, they can have a rest there and just relax. Resource rooms are organized for both typically developing children and children with disabilities and special educational needs included in mainstream education. This experience was transferred and adapted taking into account the conditions and specificity of inclusion in the Russian Federation.

In Russia a resource classroom is defined as a room in a mainstream school for special lessons where students with disabilities and special educational needs can study according to a specially adapted curriculum meeting their individual educational needs (Kozorez et al., 2016). The resource classroom model ensures the right to educate any child and allows organizing the learning process corresponding to the needs of each student in the least restrictive environment. This model helps a student to combine inclusive learning and individual one in mainstream education.

The resource classroom model implementation started about six years ago in Moscow with the project of Center of Autism problems and school № 1465 with the parents initiative, then the educational project «Inclusive molecule» (resource classrooms) was organized, it included 9 schools.

Today we can observe the resource classroom model in many Russian cities and regions: Moscow and Moscow region, Saint Petersburg, Voronezh and Voronezh region, Pyategorks region, Nizhniy Novgorod, Novosibirsk and Novosibirsk region, Smolensk, Lipetsk, Belgorod region, etc.

\section{Methodology}

The objective of the study was to generalize the experience of resource classrooms in the Russian Federation and describe the structure of the resource classroom model for inclusive education implementation. The study used theoretical research method and comparative analysis taking into account the following factors: the aim of the resource classroom model establishment, the determination of the elements for the model and their interaction, the methodological assistance, the place of this model in a mainstream school for organizing inclusive education. The documentation for Russian resource classrooms (lists with information about students with disabilities and special educational needs (their characteristics, behavior description, communication, etc.; communication lists for parents and teachers (teachers and parents can keep in touch due to such lists writing and reading the necessary information about a child, leaving massages, etc.); the examples of adapted curriculum, individual plans, timetables, etc.; job descriptions for the resource classrooms teams), 
publications dealing with the problem of inclusive education and recourse classroom in the system of mainstream schools inclusion were compared and analyzed. Materials of international conferences and webinars with the representatives of the teachers, specialists and parents implementing the resource classroom model, documents of Russian inclusive education legal and regulatory frameworks were also studied to describe the base for the establishment of such classrooms in the Russian Federation.

In particular, the authors generalized the experience of resource classrooms model as inclusive education implementation in Moscow (schools № 1321, 1540, 1367, 285, 2009, 1574, and 1206), Saint Petersburg (school № 232), Voronezh (school № 92), Saratov (schools № 57, 84) and Smolensk (school № 25), overall 12 resource classrooms were taken for experience study.

The analyzed experience allows generalaizing the organization of educational process and space, specifying the elements of the model and interaction between all the elements of the model, describe its advantages which show the effectiveness of this model.

It should be noted, that during the conducted research it was found out, that there is no proper universal structure for resource classrooms and the communication between regions is low. But due to some disability nongovernmental organizations such as «Perspectiva», "Contact» and «Inclusive Schools Association» this process is highly developing now.

\section{Research Results}

Inclusion should be a well-organized, reason out process in which each participant realizes and understands his/her role and responsibilities perfectly well.

Thus, for organizing a resource classroom in a mainstream school it is necessary to define this procedure and specify the legal and regulatory frameworks for its establishment. Based on the experience in the above mentioned schools and studied documentation it is possible to name four main steps when organizing a resource classroom: the first is a request from families raising children with disabilities or special educational needs, the second is mainstream school readiness to create special educational conditions for such children, the third is availability of a resource classroom team and the fourth is finance.

The practice of organizing for all the resource classrooms that work now suggests that at the beginning of the process there is a parents initiative. When providing the research the importance of this step was also proved by the coordinator of a resource classroom, a deputy director of the mainstream secondary school № 25 in Smolensk V. Dudareva, and the parents, being also specialists, Ye. Bagarnikova (the director of the Russian organization «Contact»), 
A. Stepanenko (a specialist of applied behavior analysis), P. Bagaradnikova (a speech pathologist), O. Pogonina. They also mentioned that parents usually unite in groups to form their request for the creation of special educational conditions at school reflected by the resource classroom model and this model allows them to realize the form of education they have chosen according to the Federal Law of December 29, 2012 No. 273-FZ "On Education in the Russian Federation". When parents are united they become the part of the inclusive process and it is a very essential action.

Practical experience shows that in most cases this request is accepted by schools and a mainstream school should follow the legal and regulatory frameworks to establish a resource classroom. From the studied documentation it is possible to name the documents necessary for the resource classroom establishment. They include:

- a warrant to establish a resource classroom;

- a resource classroom regulation;

- $\quad$ an agreement between the school and the parents (or legal guardians) of a child;

- $\quad$ an agreement between the school and the academic institution that will provide scientific and methodological support for this model;

- job description for resource classroom team;

- a resource classroom card (i.e., a description of the school staff, wage rates, facilities, equipment, etc.).

When all regulations are fulfilled, a room for a resource classroom is chosen. It is in the same building with the mainstream school. During the carried out study four basic zones were observed for work in such classrooms: a zone for individual education, a zone for group education, a working zone for a resource teacher and a zone for relaxation. Thus, the room is big enough to divide the space into these zones. The division of the resource classroom into the zones helps to organize space for students with disabilities and special educational needs appropriately.

From the compared experience of the preparation for the resource classroom work it should be noted, that at the beginning of the school year the team of the resource classroom meets with the mainstream school staff to describe the students going to be taught there and discuss the features of the resource classroom, methods and technologies which will be used during the educational process. They also give careful consideration to resource classroom students' inclusion into regular classes and think over how children with disabilities and or special educational needs will be introduced to their typically developing classmates and their parents (e.g. in schools under study teachers conduct lessons on kindness with students, place information tables and organize meetings with parents). 
Therefore, before the resource classroom starts its work, brief instructions are given to all school personnel on how to behave with students attending the resource classroom.

The purpose of the resource classroom model is to organize the inclusive education for children of disabilities and special educational needs and to provide their gradual without stress inclusion into regular classes. Therefore, having analyzed and compared the work of the resource classrooms five basic conditions can be specified for good education, social adaptation in the mainstream school environment and effective inclusion into regular classes.

The first condition is to determine a child personal adaptation period taking into consideration his/her special characteristics. It is important to indicate the features of this period organization: learning load, changing in the regime of lessons attendance, flexible timetable, etc. From the compared documentation we conclude that lessons in resource classrooms can start at 8.30 or at 9.00 and finish at 13.00 or at 13.30 . They are for 20 or 25 minutes during this period. Proper organization of the adaptation period gives an opportunity for a student with disabilities and/or special educational needs to get used to requirements, becoming more complex gradually, and the teaching team can conduct a highquality diagnostics, assess all the basic needs and capabilities of a child at a given period.

The second condition is space organization, the zones are mentioned above.

The third condition is the organization of the student educational activities. Timetable was found to be the most common example meeting this condition.

The forms of the studied timetables are different, they depend on children need, ages and characteristics (there are various forms: with photographs, pictures, symbols indicating lessons, signs, inscriptions, etc.). Such timetables help to streamline students' activities, reduce anxiety and provide a clear sequence of activity changes.

The fourth condition is teaching aids and materials adaptation. Despite there is a considerable number of aids and materials adapted for children with various educational needs (copybooks for left-handed children, copybooks for children with motor skills difficulties, etc.), the conducted study discovered that it is not possible to use them completely since a child with disability or special educational needs is included into a regular class. Therefore, for the full assimilation of the curriculum material, teachers modify and adapt the existing aids and materials, and create cards with tasks, worksheets and workbooks for students.

The fifth condition is students' progress assessment and testing. During the assessment the conditions under which the potential of each particular child is maximally revealed are organized. In this case the changes of forms for the intermediate and final assessment are provided. When choosing the form of assessment, all special educational needs and abilities of a student are considered. 
For example, children with motor skills difficulties and writing problems are provided with the opportunity for oral answers or they answer using a pad instead of doing written work. If needed, the time for the task completion is increased.

Each change in the conditions occurs due to the difficulties of a student which he/she has at present period, and they are also changed dynamically with the growth of his/ her abilities, so this process can be considered to be flexible

The experience of the schools with the resource classrooms confirms that classroom space organization and educational conditions provided in such classrooms help students with disabilities and special educational needs maintain a good state for positive learning, easer and successful inclusion into regular classes.

As in Russian schools the process of inclusive education is not easy and meets a lot of problems dealing with methodological support and absence or lack of technologies and methods for inclusion, the resource classroom can be considered the basis of the methodological assistance which is necessary for teachers of mainstream classes. It allows making the inclusion process flexible, non-traumatic and comfortable for all participants in the educational process. All resource classrooms have teams and these teams are teachers' assistants and support in working with all children.

In this team each person understands and accurately performs their professional tasks and objectives. The study of the job instructions for the resource classrooms teams made it possible to detect the participants of the educational process in the resource classroom and their responsibilities.

A well working team of a resource classroom contains a resource teacher, a tutor, a mainstream teacher, a junior supervisor (a curator) and a coordinator.

A resource teacher is responsible for organizing educational process for children receiving assistance in a resource classroom.

A tutor accompanies a student during a school day, supports him/her in the interaction with teachers and students from regular classes, conducts individual lessons, corrects students' behavior, monitors the dynamics of the student development and makes an analysis of the adaptive material, organizes joint activities with students from regular classes.

A mainstream teacher is also a member of the team. The role of mainstream teachers is very important. A mainstream teacher is responsible for students with disabilities or/and special educational needs who were accepted in the regular class, though they spend a lot of time in the resource classroom. This teacher works in close connection with tutors and resource teachers, interact with a junior supervisor (a curator), consults the resource teacher about the curriculum and plan, helps to adapt them, creates friendly environment at the lessons, gives reports about students educated in the resource classrooms. It is very important to mention, that mainstream teachers receive methodological help and support 
from the specialist. They work in close connection in the process of organizing inclusive education.

A junior supervisor (a curator) of the resource classroom can supervise some resource classrooms in different schools as his/her constant presence is not necessary. The curator's main task in the resource classroom is to provide methodological assistance to teachers working in this class.

A coordinator is a deputy director of a mainstream school implementing inclusive education. He/she is responsible for organization of interaction of resource and mainstream teachers; development of regulatory documentation governing this interaction; making up and approving the timetable according to which each student attends a resource classroom and a regular classroom; monitoring the activities of the resource classroom team, mainstream teachers and non-teaching staff (specialists such as a psychologist, a speech pathologist, a speech therapist etc.) in accordance with the approved adapted student's curriculum.

Organization of a well-arranged system for interaction between resource classroom teachers, specialists and mainstream teachers is the key for successful inclusion. All members of the team develop their professional skills and obtain specific knowledge about children they educate to make their work well done.

Basing on the generalization and comparison of the practice of the resource classroom model in schools mentioned above the optimal number of students to be educated at the resource classroom at the same time is eight. This is primarily due to the requirements for the organization of educational space. In a resource classroom there can be more than 10-12 people or even more at the same time, as the number of tutors corresponds to the number of students, and there is also a resource teacher, a mainstream teacher and, if it is necessary, other specialists are added to them.

Children, depending on their needs, study most of their time in a regular class and come to the resource classroom only for a few hours, in individual cases the resource classroom is chosen as a basic place for education (of course in accordance with their characteristics and needs). It is possible due to the fact that the structure of the resource classroom allows individualization of teaching for each student. The curriculum, materials, teaching methods, workplace and timetable are developed taking into account individual needs of each student.

Students with disabilities and special educational needs attend some lessons at the resource classroom studying individually or in a small group and they also attend other lessons together with their typically developing classmates, as it was already mentioned above. Lessons in the resource classroom take place as «one to one» (individual lessons) with a tutor or in small groups. Group lessons are conducted by a resource teacher or a mainstream teacher. 
Bliznyuk \& Senchenkov, 2020. Resource Classroom as a Model for Organizing Inclusive Education in the Russian Federation

The main feature of a resource classroom is that the students of this classroom are consistently included in the educational activities of regular classes; they can study subjects with their typically developing peers with the support of a tutor. Studying at the resource classroom helps children adapt to the mainstream school environment and learn how to behave and study together with the typically developing classmates. The percentage of joint education time for each student is different, it cannot be unified as in depends of special education needs and the process of inclusion means individual approach for every child. In practice it is possible for a student to leave a regular classroom during the lessons and go to the resource classroom if he or she has behavior that may interfere with the educational process in the regular classroom (it concerns especially children with autism spectrum disorders), as well as in the case a student requires sensory discharge.

It was found out that the main advantage of individual lessons is that a teacher gets the most control over the environment and the learning process, and it is possible to create conditions for successful learning. The most part of the lesson is conducted by a tutor. But students are also taught by other specialists (a resource teacher, mainstream teachers or specialists such as a psychologist, a speech pathologist, a speech therapist, etc.) of a resource classroom if necessary. An individual plan is created for each student. In all resource classless an individual lesson is shorter in time than a regular lesson, for example 2025 minutes depending on the student's abilities.

In the studied schools group lessons are mostly conducted by any teacher (a resource teacher, a mainstream teacher) or a specialist (for example a psychologist) as well as a tutor. A plan for all groups of students is also created taking into account their characteristic features.

Group lessons in the resource classrooms are considered to give a good opportunity to simulate a lesson in a regular class. At such lessons not only students are taught, but tutors skills to escort children are also developed.

\section{Conclusions}

The conducted study makes it possible to state the advantages of the resource classroom model, namely:

- the right for education of children with disabilities and special educational needs in mainstream schools is realized through this model;

- $\quad$ resource classrooms are organized by the parents initiative, so parents become the active participants in the inclusive education;

- $\quad$ children with disabilities and special educational needs interact with mainstream teachers and their typically developing peers which contributes to their socialization and adaptation; 
- $\quad$ proper environment, space and conditions organization of the resource classrooms make the process of inclusive education comfortable;

- $\quad$ individual approach to the education of children with disabilities and special educational needs, their personal development do not allow lowering the level of education for typically developing students;

- $\quad$ the resource classroom team and mainstream teachers have to improve their qualification constantly that contributes to professional development;

- $\quad$ due to the resource classroom model the teaching staff of a mainstream school has a permanent methodological support in organizing inclusive education.

Summarizing the above mentioned advantages, it can be concluded that the resource classroom model makes inclusion in education comfortable and effective for all members of the educational process: children with disabilities and special educational needs, typically developing children, parents and the teaching staff of schools.

\section{References}

Alekhina, S. (2013). Inclusive education for children with special educational needs. In N. Laletin (Ed.), Modern educational technologies to work with children having disabilities (pp. 71-95). Krasnoyarsk: Federal University of Siberia.

Alekhina, S. (2016). To the question of teacher's psychological readiness to inclusive education. Inclusive education: theory and practice. International conference proceedings, June 9-10, 16-20. ISBN 978-5-87471-162-7

Basov, M. (2007). General pedology grounds. St. Petersburg: Aleteya.

Blonsky, P. (1929). Difficult schoolchildren. Moscow: Education worker.

Farrell, M. (2003). Educational inclusion and raising standards. British journal of special education, 27(1), 35-38.

Federal Law of December 29, 2012 No. 273-FZ on Education in the Russian Federation. Retrieved from http://base.garant.ru/70291362/

Ivanova, N. (2011). To the question of inclusive educational program realization. Bulletin of Udmurt University, 1, 96-99.

Inclusion of Children with Special Educational Needs (2007). Dublin: Department of education and science.

Kashchenko, V. (2010). Pedagogical correction: changing of character deficiency for children and adolescents. Moscow: Academia.

Kozorez, A. et al. (2016). Resource classroom: Experience in organizing teaching and extracurricular activities of children with autism spectrum disorders in mainstream schools. Moscow: ANO "Resource class".

Kutepova, E. (2015). In M. Betyanova (Ed.). The conditions for education of a child with disabilities. Inclusive education (pp. 21-33). Moscow: Supervising teachers and pupils upbringing.

Lazursky, A., \& Nechaev, A. (1910). The emotional life of children: Essays on educational psychology. Moscow: Polza. 
Bliznyuk \& Senchenkov, 2020. Resource Classroom as a Model for Organizing Inclusive Education in the Russian Federation

Liferov, A. (1997). Global education- the way to integration of the world educational space. Moscow: Pedagogical search.

Loshakova, I., \& Yarskaya-Smirnova, E. (2002). Integration in the conditions of differentiation: the problems of inclusive education for children with disabilities. Socio-psychological problems of education of non-typical children. Sarotov: Saratov Pedagogical Institute.

Luria, A. (1973). Principles for selecting children for special schools. Moscow: Prosvescheniye.

Malofeev, N. (2009). Special education in the changing world. Europe. Moscow: Prosvescheniye.

The letter of the Ministry of education of the Russian Federation of July 7, 2017 No.TC-267/07 About information direction. Retrieved from https:/www.garant.ru/products/ipo/ prime/doc/71660690/

Vygotsky, L. (2012). Pedagogical psychology. Moscow: Astrel.

Vygotsky, L. (1936). Diagnostics of development and pedological clinic of difficult childhood. Moscow: Experiment.

Yarskaya-Smirnova, E., \& Loshakova, I. (2003). Inclusive education for children with disabilities. Social studies.5, 100-106.

Yekzhanova, E. (2011). Two-component inclusive model for ensuring the rights for education of children with different levels of psychophysical development. Inclusive education, methodology, practice, technology. International conference proceedings, June 20-22, 23-24. 